Saudi Journal of Medicine

Abbreviated Key Title: Saudi J Med ISSN 2518-3389 (Print) |ISSN 2518-3397 (Online) Scholars Middle East Publishers, Dubai, United Arab Emirates

Journal homepage: https://saudijournals.com/sjm

Original Research Article

\title{
Serial Estimation of Neutrophil-to-Lymphocyte Ratio Predicts Progress of Critical Illness in Patients with COVID-19 Disease
}

\author{
Abdullah Al Jadidi, MD ${ }^{1}$, Mohammad Azharuddin Malik, $\mathrm{MD}^{2}$, Naresh Kumar Kaul, MD ${ }^{3 *}$, Rashid M Khan, MD ${ }^{3}$ \\ ${ }^{1}$ OMSB, Fellow in Neuroanesthesia \& Neuro-Critical Care (UK), Department of Anesthesia \& ICU, Khoula Hospital, Muscat, Sultanate of Oman \\ ${ }^{2}$ DM, FACC, Department of Cardiology, Jawahar Lal Nehru Medical College, Aligarh Muslim University, Aligath, India \\ ${ }^{3}$ Department of Anesthesia \& ICU, Khoula Hospital, Muscat, Sultanate of Oman
}

DOI: $\underline{\text { 10.36348/sjm.2020.v05i09.003 }}$ | Received: 09.09.2020 | Accepted: 17.09.2020 | Published: 19.09 .2020

*Corresponding Author: Naresh Kumar Kaul

\section{Abstract}

A high incidence of lymphopenia has been reported in Covid-19 patients. The initial neutrophil-to-lymphocyte ratio (NLR) of $\geq 3.13$ in Covid-19 patients predicts a high propensity of these patients to progress to critical illness. However, it has not yet been established if NLR would start to lower towards a normal ratio of 1-3 during patient's road to recovery. This study hypothesized that NLR would start to return towards normal as patients recovered from this illness. This study included 43 patients with Covid-19 infection treated in the ICU at Khoula Hospital, Muscat from $10^{\text {th }}$ May to $5^{\text {th }}$ August 2020. Seven readings of NLR (NLR1 to NLR7) from the time of going on ventilator (NLR1) to discharge of patient (NLR7) from the ICU were statistically analyzed using paired ' $t$ ' test for patients who recovered or those who died. NLR values demonstrated a progressive fall in patients who recovered when comparison was made between NLR1 with other readings (NLR2 to NLR7). On the contrary, insignificant changes in NLR values were observed when comparison was made between NLR1 with subsequent day's readings in patients who died while in ICU. In conclusion, this study suggests that the NLR of patients who survived showed a downward trend from its initial high values. In contrast, patients who died while in the ICU, NLR values showed little change from their basal value.

Keywords: neutrophil-to-lymphocyte ratio, Covid-19.

Copyright @ 2020: This is an open-access article distributed under the terms of the Creative Commons Attribution license which permits unrestricted use, distribution, and reproduction in any medium for non-commercial use (NonCommercial, or CC-BY-NC) provided the original author and source are credited.

\section{INTRODUCTION}

Coronavirus is a member of a large virus family. They are responsible for common cold and other serious illnesses, such as the Middle East respiratory syndrome and severe acute respiratory syndrome [1-4].

Lymphopenia is frequently encountered during these viral infections [5, 6]. Most recently, in 2019 we have had the coronavirus disease (COVID-19) that has been the cause of unexplained viral pneumonia resulting in mild to critical illness [7]. A high incidence of lymphopenia has been reported in COVID-19 patients by Huang and his colleagues [8]. Later in the same year, Liu et al., [9] reported that the initial neutrophil-to-lymphocyte ratio (NLR) of $\geq 3.13$ in patients who were $\geq 50$ years was predictive of high propensity of these patients to progress to critical illness. However, they did not follow-up NLR ratio to observe whether this would start to lower towards a normal ratio of 1-3 [10,11] during their road to recovery from Covid-19 infection.
We hypothesized that NLR would start to reduce as lymphocyte numbers start to rise during the recovery phase of Covid-19 illness and hence could be a potential predictor of a healthy recovery. To test this hypothesis, we included 43 consecutive patients with documented Covid-19 positivity who were critically ill and admitted to our intensive care unit for ventilatory management from $10^{\text {th }}$ May to August 9th 2020.

\section{METHODOLOGY}

This was a prospective single-center study, which included 43 patients with COVID-19 infection treated in the ICU at Khoula Hospital, Muscat from $10^{\text {th }}$ May to $5^{\text {th }}$ August 2020. Permission to retrieve patient's data for analysis and reporting was obtained from Departmental Management Board. All 43 patients were shifted to our ICU after meeting the following criteria: confirmation of COVID-19 as per polymerase chain reaction test of respiratory or blood samples that was positive for the nucleic acid of COVID-19. In addition, they had more than one clinical features such as fever and/or respiratory distress with respiratory rate $\geq 30$ beats/min; mean oxygen saturation < $92 \%$ while receiving $>5 \mathrm{~L} / \mathrm{min} \mathrm{O} 2$; hypotension not responding to 
initial fluid bolus or requiring vasopressors; arterial blood oxygen partial pressure/oxygen concentration < $300 \mathrm{mmHg}$, acidosis with a $\mathrm{pH}<7.3$ or $\mathrm{PCO} 2>50$ $\mathrm{mmHg}$, evidence of acute end organ involvement and/or patients with rapidly progressive respiratory failure.

All patients were transferred after intubation from referring hospital or were intubated in our ICU on admission and put on appropriate mode of mechanical ventilatory support. After admission, the patients were closely monitored for laboratory indices and imaging analysis. Patients' treatment modality and outcome events were recorded. Complete blood cell count was assessed almost every alternate day from which we calculated the NLR. The attending intensivist was free to adopt any appropriate treatment modality including use of antiviral, antibiotic and steroids. If the treating intensivist decided to start corticosteroids, methylprednisolone $40 \mathrm{mg}$ every $12 \mathrm{hr}$ for 5-7 days was administered. However, a few patients received dexamethasone in place of methylprednisolone while few received none.

None of the patients received plasma therapy while in ICU at Khoula Hospital though a few had received it before being shifted to our institution from feeding hospitals. The endpoint of this study was successful tracheal extubation, discontinuation of any form of ventilatory support and discharge of the patient to the ward/ referring institution or death of the patient while still on ventilatory support.

Since the duration of patient's ventilatory and ICU management ranged from 5 days to over 2 month, we have presented NLR in Table- 2 and other tables as follows: NLR1 value on the first day of ventilatory support, thereafter two initial readings on alternate day (NLR2 and NLR3), a middle reading of stay in ICU (NLR4), two readings just prior to tracheal extubation (NLR5 and NLR6) and one reading on the day of discharge to the ward (NLR7). We could not continue to monitor NLR of these patients after discharge from our ICU as several of them were directly transferred to their parent referring hospital. We could therefore assess the progress of NLR only till these patients were discharged from our ICU by analyzing these seven readings.

\section{STATISTICAL ANALYSIS}

Paired ' $\mathrm{t}$ ' test was used for statistical analysis in Table 2 data. $\mathrm{P}<0.05$ has been taken as statistically significant finding for this study. Analyses were performed using SPSS 22.0 statistical package (SPSS, Inc., Chicago, IL, USA).

\section{RESULTS}

The mean age of patients who recovered and were discharged from ICU was nearly identical to those who died while in ICU. In addition, no difference was noted in recovery rate of male and female patients in our ICU (Table-1).

When the NLR1 value was compared with NLR2 to NLR7 in all 43 patients, a gradual reduction in its value was clearly evident. This reduction reached level of significance ( $\mathrm{p}=0.05$ or less) from NLR4 onwards (Table-2).

Table-2 also showed that NLR values demonstrated a progressive fall in patients who recovered when comparison was made between NLR1 with other readings (NLR2 to NLR7). This difference became especially significant when NLR1 was compared to NLR3 to NLR7. This finding denotes that there is an improvement in lymphocyte numbers in patients who survive.

Table-2 further goes on to show that there were insignificant changes in NLR values when comparison was made between NLR1 with subsequent day's readings in patients who died while in ICU. This finding denotes that there is poor improvement in lymphocyte numbers in patients who died during their stay in the ICU.

The mortality rate in our ICU for Covid-19 patients was $27.9 \%$ (Table-3). These patients spent shorter period in the ICU (12.67 days) as compared to those who survived (17.58 days)

Table-1: Showing demographic data of Covid-19 patients in ICU at Khoula Hospital

\begin{tabular}{|l|l|l|l|l|l|}
\hline $\begin{array}{l}\text { Mean age of } \\
\text { all } 43 \text { patients } \\
(y r) \text { Mean } \pm\end{array}$ & $\begin{array}{l}\text { Sex ratio of all 43 } \\
\text { patients Numbers } \\
(\%)\end{array}$ & $\begin{array}{l}\text { Mean age of } \\
\text { patients who } \\
\text { SD }\end{array}$ & $\begin{array}{l}\text { Mean age of } \\
\text { patients who died } \\
\text { recovered in ICU } \\
\text { while in ICU }\end{array}$ & $\begin{array}{l}\text { Number of male } \\
\text { patients } \\
\text { discharged from }\end{array}$ & $\begin{array}{l}\text { Number of } \\
\text { female patients } \\
\text { discharged from } \\
\text { (Yr) Mean } \pm \text { SD }\end{array}$ \\
\hline $53.79 \pm 15.68$ & $34(79.1): 9(20.9)$ & $54.0 \pm 14.02$ & $53.25 \pm 20.0$ & $24 / 34: 70.6$ & $7 / 9: 77.7$ \\
\hline
\end{tabular}

$\pm \mathrm{SD}=$ Standard Deviation, $\mathrm{yr}=$ year, No.= Number of patients 
Table-2: Neutrophil/Lymphocyte Ratio of all patients who were admitted to the ICU according to their recovery or death in the ICU

\begin{tabular}{|l|l|l|l|l|l|l|}
\hline & \multicolumn{3}{|l|}{ All Patients } & Discharged & Deaths & \\
\cline { 2 - 7 } & Mean \pm SD & *P-Value & Mean \pm SD & *P-Value & Mean \pm SD & *P-Value \\
\hline NLR 1 & $16.11 \pm 12.52$ & --- & $17.0 \pm 14.1$ & -- & $13.9 \pm 7.7$ & -- \\
\hline NLR 2 & $12.95 \pm 7.69$ & 0.05 & $12.9 \pm 7.9$ & 0.06 & $13.0 \pm 7.4$ & 0.64 \\
\hline NLR 3 & $10.85 \pm 6.41$ & 0.01 & $9.5 \pm 5.8$ & 0.004 & $13.8 \pm 6.9$ & 0.95 \\
\hline NLR 4 & $11.14 \pm 10.83$ & 0.05 & $9.1 \pm 8.0$ & 0.009 & $16.7 \pm 15.4$ & 0.75 \\
\hline NLR 5 & $10.36 \pm 12.09$ & 0.03 & $7.7 \pm 4.6$ & 0.001 & $18.1 \pm 21.8$ & 0.71 \\
\hline NLR 6 & $6.66 \pm 4.05$ & $<0.001$ & $5.6 \pm 2.3$ & $<0.001$ & $11.1 \pm 6.5$ & 0.13 \\
\hline NLR 7 & $6.29 \pm 5.18$ & $<0.001$ & $5.1 \pm 2.7$ & $<0.001$ & $12.4 \pm 9.6$ & 0.51 \\
\hline
\end{tabular}

$\mathrm{NLR}=$ Neutrophil/ Lymphocyte ratio, $\pm \mathrm{SD}=$ Standard Deviation. *P-Values are for paired comparisons of baseline NLR on day 1 with subsequent values.

Table-3: Showing final outcome of the 43 Covid-19 patients

\begin{tabular}{|l|l|l|}
\hline Patients Group & No. of patients (\%) & Days in ICU Mean $( \pm$ SD) \\
\hline Discharged from ICU & $31(72.09)$ & $17.58(11.37)$ \\
\hline Died in ICU & $12(27.9)$ & $12.67(5.61)$ \\
\hline
\end{tabular}

$$
\text { No.= Number }
$$

\section{DISCUSSION}

Lymphopenia at the time of admission to the hospital has been a prominent feature in patients who suffered from $\mathrm{H} 5 \mathrm{~N} 1$ infection resulting in severe or fatal outcome. In addition, lymphopenia has also been a hallmark of severe H7N9 influenza virus infection [12]. We too noted marked lymphopenia in all our Covid-19 patients who were admitted to the ICU.

A number of mechanisms have been put forward to explain the cause of lymphopenia in patients with moderate to severe viral infection. First, an increased cytokine level is the host immune response to severe coronavirus infection. Studies have confirmed that this increased proinflammatory cytokines play a critical role in the induction of lymphopenia [13]. Second, Panesar observed that the most probable cause of lymphopenia in viral infection is the high level of glucocorticoids [14]. This has been confirmed by noting a higher cortisol levels in SARS patients with lymphopenia [15]. This higher quantity of endogenous corticosteroids released into the blood circulation impacts the lymphocytes, causing migration of $\mathrm{T}$ lymphocytes out of the peripheral circulation [16] and apoptosis [17] thereby resulting in lymphopenia. Lastly, it has been recently reported that COVID-19 virus may damage the $\mathrm{T}$ lymphocytes directly as well. This may play an important role in lowering lymphocyte count in addition to the role played by endo- or exogenous steroids. A low lymphocyte count is an important factor that causes deterioration of the patient's condition [18].

Liu et al., used NLR for early prognosis of the course of the Covid 19 disease and thereby help reduce mortality and alleviate the shortage of medical resources [9]. We decided to take it one step forward and analyzed NLR during the recovery or fatality stage of their illness in our ICU as an indicator of the progress of Covid 19 disease.
We hypothesized that repletion of lymphocytes could be one of the key factors to recovery from COVID-19 and hence a falling NLR would be harbinger of recovery from illness. This study proved our hypothesis to be true. We noted that the NLR gradually reduced in those patients who recovered in contrast to minimal changes in NLR in patients who succumbed to this disease. This finding would be of some help in counseling the patient and their relatives on the possible outcome of patient's management.

There are several other factors that may influence the Covid 19 outcome, other than NLR. These include smoking, diabetes, hypertension and COPD [19]. These may not have influenced the results in the present study because of the low number of subjects with comorbidities. We had a total of only ten patients with associated comorbidities.

Other than smoking and associated comorbid medical conditions that influence patient outcome, treatment with glucocorticoids is known to complicate the issue regarding lymphopenia in SARS patients. Most of these SARS patients were empirically treated with a combination of antibacterial, antiviral and supraphysiological doses of glucocorticoids [20, 21]. It has been reported that whilst the SARS patients who had not received exogenous glucocorticoids exhibited mild to moderate lymphopenia, the lymphocyte count decreased further in patients who were given steroids [22]. This certainly suggests glucocorticoids had a role in the development of lymphopenia. The lymphopenia in the former group may just have been a prognostic factor of the stress response, involving the hypothalamic-pituitary-adrenal (HPA) axis [23]. An intact HPA axis is capable of secreting 225-440 mg of cortisol under extreme stress, and achieving blood levels in the range $830-7220 \mathrm{nmol} / \mathrm{L}$ [24]. As per our 
hospital's ICU policy, steroids were administered to all except $4(9.30 \%)$ of our patients for a period of 5-7 days. We could not study its role on lymphopenia in the absence of a control group.

There were some limitations in this study. First, we performed this study in low number of subjects. Second, we could not follow the patient's progress beyond their stay in our ICU as many had to be discharged directly to their referring institutions and hence the study could not include data of the final survival outcome of patients. Lastly, the management strategy of the patient was not standardized.

In conclusion, our study suggests that the NLR of patients who survived showed a downward trend from its initial high values. In contrast, patients who died while in the ICU, NLR values showed little change from their basal value.

\section{REFERENCES}

1. Kuiken, T., Fouchier, R. A., Schutten, M., Rimmelzwaan, G. F., Van Amerongen, G., Van Riel, D., ... \& Ling, A. E. (2003). Newly discovered coronavirus as the primary cause of severe acute respiratory syndrome. The Lancet, 362(9380), 263-270.

2. Drosten, C., Günther, S., Preiser, W., Van Der Werf, S., Brodt, H. R., Becker, S., ... \& Berger, A. (2003). Identification of a novel coronavirus in patients with severe acute respiratory syndrome. New England journal of medicine, 348(20), 1967-1976.

3. de Groot, R. J., Baker, S. C., Baric, R. S., Brown, C. S., Drosten, C., Enjuanes, L., ... \& Perlman, S. (2013). Commentary: Middle east respiratory syndrome coronavirus (mers-cov): announcement of the coronavirus study group. Journal of virology, 87(14), 7790-7792.

4. Zaki, A. M., Van Boheemen, S., Bestebroer, T. M., Osterhaus, A. D., \& Fouchier, R. A. (2012). Isolation of a novel coronavirus from a man with pneumonia in Saudi Arabia. New England Journal of Medicine, 367(19), 1814-1820.

5. Naeim, F., Rao, P. N., Song, S. X., \& Grody, W. W. (2013). Atlas of Hematopathology. Morphology, Immunophenotype, Cytogenetics, and Molecular Approaches. 1st edition. (pp. 627628). San Diego, CA: Elsevier Science Publishing Co Inc.

6. Longo, D. L., Fauci, A., Kasper, D., Hauser, S., Jameson, J. L., \& Loscalzo, J. (2011). Harrison's Principles of Internal Medicine. 18th edition. Columbus, OH: McGraw-Hill.

7. Holshue, M. L., DeBolt, C., Lindquist, S., Lofy, K. H., Wiesman, J., Bruce, H., ... \& Diaz, G. (2020). First case of 2019 novel coronavirus in the United States. New England Journal of Medicine. 382(10):929-936.

8. Huang, C., Wang, Y., Li, X., Ren, L., Zhao, J., Hu,
Y., ... \& Cheng, Z. (2020). Clinical features of patients infected with 2019 novel coronavirus in Wuhan, China. The lancet, 395(10223), 497-506.

9. Liu, J., Liu, Y., Xiang, P., Pu, L., Xiong, H., Li, C., ... \& Song, M. (2020). Neutrophil-tolymphocyte ratio predicts critical illness patients with 2019 coronavirus disease in the early stage. Journal of Translational Medicine, 18, 1-12.

10. Lee, J. S., Kim, N. Y., \& Shin, S. C. (2018). Reference values of neutrophil-lymphocyte ratio, lymphocyte-monocyte ratio, platelet-lymphocyte ratio, and mean platelet volume in healthy adults in South Korea. Medicine, 97(26): e11138.

11. Moosazadeh, M., Maleki, I., \& Barzegar, A. (2019). Normal ratio of neutrophil-to-lymphocyte ratio, lymphocyte-to- monocyte ratio and plateletto-lymphocyte ratio among Iranian population: Results of Tabari cohort. Caspian J Intern Med, 10(3): 320-325.

12. Chen, Y., Liang, W., Yang, S., Wu, N., Gao, H., Sheng, J., ... \& Li, Y. (2013). Human infections with the emerging avian influenza A H7N9 virus from wet market poultry: clinical analysis and characterisation of viral genome. The Lancet, 381(9881), 1916-1925.

13. Dierckx, T., Khouri, R., Menezes, S., Decanine, D., Farre, L., Bittencourt, A., \& Weyenbergh, J. (2017). IFN- $\beta$ induces greater antiproliferative and proapoptotic effects and increased p53 signaling compared with IFN- $\alpha$ in PBMCs of adult T- cell leukemia/lymphoma patients. Blood Cancer Journal, 7(1), e519.

14. Panesar, N. S. (2003). Lymphopenia in SARS. Lancet, 361(9373): 1985.

15. Panesar, N. S., Lam, C. W. K., Chan, M. H. M., Wong, C. K., \& Sung, J. J. Y. (2004). Lymphopenia and neutrophilia in SARS are related to the prevailing serum cortisol. Eur J Clin Invest, 34 (5): 382-384.

16. Fauci, A. S., Dale, D. C., \& Balow, J. E. (1976). Glucocorticosteroid therapy: mechanisms of action and clinical considerations. Ann Intern Med, 84 (3): 304-315.

17. Robertson, A. M., Bird, C. C., Waddell, A. W., \& Currie, A. R. (1978). Morphological aspects of glucocorticoid-induced cell death in human lymphoblastoid cells. J Pathol, 126(3): 181-187.

18. Liu, W. J., Zhao, M., Liu, K., Xu, K., Wong, G., Tan, W., \& Gao, G. F. (2017). T-cell immunity of SARS-CoV: Implications for vaccine development against MERS-CoV. Antiviral research, 137, 8292.

19. Leung, J. M., Yang, C. X., Tam, A., Shaipanich, T., Hackett, T. L., Singhera, G. K., ... \& Sin, D. D. (2020). ACE-2 expression in the small airway epithelia of smokers and COPD patients: implications for COVID-19. European Respiratory Journal, 55(5):2000688.

20. Ho, J. C., Ooi, G. C., \& Mok, T. Y. (2003). Highdose pulse versus nonpulse corticosteroid 
regimens in severe acute respiratory syndrome. $A m$ J Respir Crit Care Med, 168(12):1449-1456.

21. Sung, J. J. Y., Wu, A., Joynt, G. M. (2004). Severe acute respiratory syndrome: report of treatment and outcome after a major outbreak. Thorax, 59(5):414-420.
22. Gu, J., Gong, E., \& Zhang, B. (2005). Multiple organ infection and the pathogenesis of SARS. $J$ Exp Med, 202(3):415-424.

23. Panesar, N. S. (2003). Lymphopenia in SARS. Lancet, 361(9373):361:1985

24. Thompson, B. T. (2003). Glucocorticoids and acute lung injury. Crit Care Med, 31(4):S253S257. 